A C T A UN IVER S T A T IS N I C O L A I C OP E R N I C I EKONOMIA XXXIX - NAUKI HUMANISTYCZNO-SPOŁECZNE - ZESZTYT 389 - TORUŃ 2009

Uniwersytet Mikołaja Kopernika w Toruniu

Katedra Ekonometrii i Statystyki

Sylwester Bejger

\title{
EKONOMETRYCZNE NARZĘDZIA DETEKCJI RÓWNOWAGI ZMOWY W BRANŻY
}

\begin{abstract}
$\mathrm{Z}$ a ry s t r e ś c i. W artykule przedstawiono problem detekcji równowagi zmowy jawnej lub milczącej w kontekście wyboru właściwej metody ekonometrycznej, który determinowany jest ilością informacji posiadaną przez obserwatora. Zaprezentowano jeden z markerów zmowy spójnych z równowagą właściwego modelu interakcji strategicznej - obecność zaburzeń strukturalnych $w$ wariancji procesu ceny dla faz zmowy i konkurencji. Jako poprawną teoretycznie metodę detekcji tego typu zmian bez wiedzy a priori o momentach przełączania zaproponowano wykorzystanie przełącznikowego modelu Markowa z przełączaniem reżimów wariancji. W celu weryfikacji skuteczności metody aplikowano ją dla szeregu cen rynkowych lysiny w czasie trwania i upadku zmowy jej producentów.
\end{abstract}

$\mathrm{S} \nmid$ o w a $\mathrm{k} 1 \mathrm{u} \mathrm{c} \mathrm{z} \mathrm{o} \mathrm{w} \mathrm{e:} \mathrm{Zmowa} \mathrm{jawna} \mathrm{i} \mathrm{milcząca,} \mathrm{równowaga,} \mathrm{lysina,} \mathrm{wariancja} \mathrm{ceny,} \mathrm{model}$ przełącznikowy Markowa

\section{WSTĘP}

Równowaga zmowy graczy w branży może być konsekwencją interakcji strategicznej graczy o charakterze zmowy jawnej (overt collusion) lub zmowy milczącej (tacit collusion). Mimo, iż oba rodzaje interakcji opisane są odmiennymi modelami teorii gier $\mathrm{z}$ różnymi założeniami informacyjnymi, to ich równowagi charakteryzują się podobnymi konsekwencjami dla branży, tzn:

a) występowaniem siły rynkowej graczy, prowadzącej do strat bogactwa społecznego (ponadnormalny PCM),

b) ograniczeniem konkurencji i zahamowaniem rozwoju branży.

$\mathrm{W}$ artykule zaprezentowano jeden $\mathrm{z}$ markerów zmowy wynikających $\mathrm{z}$ teoretycznego modelu zmowy milczącej jakim jest sztywność cen w fazie zmowy oraz zaproponoowano wykorzystanie przełącznikowego modelu Markowa typu MS-AR-GARCH celem detekcji zmian strukturalnych w wariacji ceny rynkowej i tym samym weryfikacji obecności wymienionego markera. Problemem 
badawczym jest wstępna weryfikacja przydatności zaproponowanej metody ekonometrycznej. W tym celu, w części empirycznej aplikowano zaproponowany model dla szeregu cen rynkowych kartelu graczy - producentów lysiny.

\section{ZMOWA I JEJ DETEKCJA ILOŚCIOWA}

Zmowa jest poważnym problemem gospodarki rynkowej. Rozważając jedynie zmowy jawne (głownie na obszarze raportowania anglojęzycznego) w okresie 1990-2005 potwierdzono 283 kartele (tzw. hard core cartels) o zasięgu krajowym i globalnym, przy czym ocenia się, że zaledwie $30 \%$ istniejących zmów jawnych podlega wykryciu i ukaraniu. Nie ma danych dotyczacych zmów milczących. Wspomniane 283 kartele wpłynęły na sprzedaż o wartości 2,1 biliona USD, spowodowały nieuzasadnione zawyżenie cen (price overcharge) o wartości 500 mld USD oraz nałożono na nie kary pieniężne o wartości nominalnej 25,4 mld USD ${ }^{1}$.

Biorąc pod uwagę powszechność oraz szkodliwość zmów naturalnym wydaje się chęć ich szybkiej detekcji. Niestety, o ile teoretyczne modele zmowy jawnej lub milczacej są dobrze określone jako hipotezy badawcze dotyczące zachowania graczy ${ }^{2}$, to ich empiryczna weryfikacja nastręcza ogromne trudności. Dzieje się tak przede wszystkim, dlatego iż gracze uczestniczące w zmowie maja przewagę nad obserwatorem w postaci prywatnych informacji. Poza tym często zasób statystyki publicznej jest więcej niż skromny na poziomie dezaagregacji branżowej lub poszczególnych graczy. Nietrudno zatem skonstatować, iż szczególnie cenne są metody ekonometryczne z jednej strony oszczędne, jeśli chodzi o wykorzystanie danych statystycznych, z drugiej spójne z hipotezą modelową. Znane obecnie metody ekonometryczne detekcji zmowy dzielą się na metody bezpośrednie i pośrednie:

a) bezpośrednie - oszacowanie profilu strategii $\mathrm{w}$ równowadze zgodnego z założonym modelem zmowy, weryfikacja hipotezy o zgodności $z$ równowagą teoretyczna,

b) pośrednie - pomiar i/lub identyfikacja siły rynkowej lub detekcja tzw. znaczników zmowy (zachowań niekonkurencyjnych) czyli pewnych charakterystycznych dla zmowy zaburzeń dotyczących:

- związku pomiędzy cenami graczy, a zmianami popytu rynkowego,

- stabilności cen i udziałów w rynku,

- związku pomiędzy cenami graczy,

- inwestycji w potencjał produkcyjny.

\footnotetext{
${ }^{1}$ Szerzej patrz: Connor, Helmers (2006).

${ }^{2}$ Szerzej na temat ogólnej procedury badawczej stopnia monopolizacji branży patrz: Bejger (2004)
} 
Metody grupy a) są bardzo wymagające, jeśli chodzi o dane statystyczne i ich aplikacje, są bardzo rzadkie, możliwe w specyficznych warunkach ${ }^{3}$. Metody grupy b) są znacznie bardziej popularne. Podstawowe z nich, wymienione w kolejności intensywności wykorzystania danych statystycznych, to:

- badanie zaburzeń strukturalnych zmienności cen,

- metoda nieparametryczna, opartą na preferencjach ujawnionych,

- test Osborne-Pitchik,

- badanie asymetrii reakcji cenowych,

- metoda Halla,

- estymacja elastyczności popytu rezydualnego,

- metoda Panzar-Rosse,

- metoda CPM.

\section{ZABURZENIA CEN CHARAKTERYSTYCZNE DLA ZMOWY}

Jednymi z najbardziej obiecujących markerów zmowy są markery oparte na analizie zmian procesów cen i/lub udziałów w rynku. Zgodnie ze znanymi modelami zmowy milczącej:

1) cena i podaż gracza (y) są ujemnie skorelowane, cena wyprzedza cykl popy$\mathrm{tu}$, proces stochastyczny ceny rynkowej podlega zmianom typu reżimowe$\mathrm{go}^{4}$,

2) wariancja procesu ceny jest średnio niższa dla faz zmowy i może podlegać zmianom typu reżimowego ${ }^{5}$,

Wydaje się, iż szczególnie obiecującym w praktyce może być zastosowanie markera $\mathrm{nr}$ 2. Uzasadnione jest to tym, iż wymagania dotyczące danych są dla tego markera bardzo make (wystarczy cena rynkowa) oraz ma on swoje jasne uzasadnienie teoretyczne. Mniejsza zmienność cen w fazie zmowy wynika bezpośrednio z własności równowagi typu SPPE (symetric perfect public equilibrium) supergry cenowej ze standardowym założeniem o dostatecznie wysokim współczynniku dyskonta. Dla profilu strategii w równowadze tej gry gracze:

- osiagają wypłaty wyższe niż w równowadze konkurencyjnej (wypłaty kartelowe),

- w fazie zmowy ceny graczy są niewrażliwe na zaburzenia kosztowe (gracze unikają zmian cen, nawet kosztem efektywności, aby nie powodować przełaczenia do fazy kary).

\footnotetext{
${ }^{3}$ Można tu wymienić np: Slade (1992).

${ }^{4}$ Patrz: Green, Porter (1984), Haltiwanger, Harrington (1991), Rotemberg, Saloner, (1986).

5 Patrz: Bolotova, Connor, Miller, (2008), Abrantes-Metz, Froeb, Geweke, Taylor (2006), Athey, Bagwell, Sanchirico (2004), Connor (2004).
} 
Wśród wad markera trzeba wskazać konieczność dysponowania szeregiem obserwacji obejmującym zarówno fazy konkurencji jak i zmowy oraz wysoką homogeniczność produktu branży poddanej analizie.

\section{EKONOMETRYCZNA METODA WERYFIKACJI OBECNOŚCI MARKERA}

Dotychczasowe prace związane $\mathrm{z}$ detekcją zmowy na podstawie detekcji zmian strukturalnych $\mathrm{w}$ wariancji obejmowały zastosowanie metod statystyki opisowej dla porównania poziomów wariancji w fazach zmowy i konkurencji (Abrantes-Metz, Froeb, Geweke, Taylor, 2006) oraz zastosowania dla procesu ceny rynkowej specyfikacji ARCH/GARCH wraz z dodatkową zmienną 0-1 opisującą fazy zmowy i konkurencji (Bolotova, Connor, Miller, 2008, dalej BCM ).

$\mathrm{W}$ artykule niniejszym proponuje się zastosowanie jako metody ekonometrycznej dla weryfikacji markera, przełącznikowego, modelu Markowa typu $\operatorname{MS}(M)(A R(p)) G A R C H(p, q)$ dla wariancji i/lub średniej (stałej) procesu ceny ${ }^{6}$. Zastosowanie takiego modelu ma następujące zalety:

- jest to metoda spójna teoretycznie ze strukturą strategii równowagi modelu supergry,

- pozwala na bezpośrednie modelowanie zmian strukturalnych zmienności procesu, bez użycia dodatkowych zmiennych sztucznych, modelowanie takie nie jest możliwe w np. w specyfikacji ARCH/GARCH,

- jest spójny $\mathrm{z}$ asymetrią informacyjną pomiędzy uczestnikami kartelu a obserwatorem. Specyfikacja MS(AR)GARCH nie wymaga obserwacji (znajomości) zmiennej stanu, czyli może służyć faktycznej detekcji reżimów wariancji i obiektywnemu ustaleniu momentów przełączania, a więc detekcji faz zmowy i konkurencji. Postać ogólna modelu $\operatorname{MS}(\mathrm{M})(\operatorname{AR}(\mathrm{p})) \mathrm{GARCH}(\mathrm{p}, \mathrm{q})$ jest wersją rozwojową dobrze znanego modelu $\mathrm{MS}^{7}$. Aplikacje modelu $\mathrm{z}$ reżimami $\mathrm{w}$ wariancji dotyczą głównie danych o wysokiej częstości, takich jak kursy walutowe, stopy zwrotu z instrumentów finansowych, ceny energii elektrycznej ${ }^{8}$.

Ogólna postać modelu przełącznikowego, jaki zastosowano może ${ }^{9}$ być zapisana jako:

\footnotetext{
${ }^{6}$ Według taksonomii Krolziga model taki można określić jako MSI(M)H-AR(q) ze składnikiem GARCH(p,q). Patrz: Krolzig (1998).

${ }^{7}$ W zakresie specyfikacji i metod estymacji patrz np. Hamilton (1989), Hamilton, J. D., Susmel (1994), Krolzig (1998), Stawicki (2004), Davidson (2004).

${ }^{8}$ Patrz np. Fong (1998), Włodarczyk, Zawada (2005, 2007), Kośko, Pietrzak (2007).

${ }^{9}$ Stosuje się różne notacje, podana tutaj pochodzi z Davidson (2004).
} 


$$
y_{t}=\alpha_{0 S_{t}}+\sum_{m=1}^{p} \phi_{m S_{t}} y_{t-m}+u_{t}
$$

gdzie:

$$
\begin{aligned}
& u_{t}=h_{t}^{1 / 2} e_{t} \text { oraz } e_{t} \sim \text { i.i.d. }(0,1) \\
& h_{t}=\beta_{0 S_{t}}+\sum_{m=1}^{\infty} \beta_{m S_{t}} u_{t-m}^{2}
\end{aligned}
$$

W równaniu wariancji warunkowej (2) zastosowano specyfikację $\mathrm{ARCH}(\infty)$, która zawiera także modele klasy GARCH $(\mathrm{p}, \mathrm{q})$.

W modelu (1),(2) każdy z parametrów może być potencjalnie zmienną losową, przełączaną pomiędzy wartościami ze skończonego zbioru wartości, zależnych od aktualnego stanu $S_{t}$. gdzie $S_{t}=1, \ldots, M$.

Zakłada się, iż zmienna $S_{t}$ jest egzogenicznym, jednorodnym procesem Markowa o stałych prawdopodobieństwa przejścia $\left\{p_{i j}\right\}$, takich, że:

$$
p_{i j}=\operatorname{Pr}\left(S_{t}=j \mid S_{t-1}=i\right) .
$$

Prawdopodobieństwo tego, że obserwowany proces $y_{t}$ jest w stanie $j \mathrm{w}$ okresie $t$ dane jest za pomocą równania filtrującego (uaktualniającego):

$$
\operatorname{Pr}\left(S_{t}=j \mid \Omega_{t}\right)=\frac{f\left(y_{t} \mid S_{t}=j, \Omega_{t-1}\right) \operatorname{Pr}\left(S_{t}=j \mid \Omega_{t-1}\right)}{\sum_{i=1}^{M} f\left(y_{t} \mid S_{t}=i, \Omega_{t-1}\right) \operatorname{Pr}\left(S_{t}=i \mid \Omega_{t-1}\right)},
$$

gdzie $\Omega_{t}$ oznacza całą informację ( $\mathrm{tj} . y_{t-j}, S_{t-j}, j \geq 0$ ) dostępną w chwili $t$, oraz:

$$
\operatorname{Pr}\left(S_{t}=j \mid \Omega_{t-1}\right)=\sum_{i=1}^{M} p_{i j} \operatorname{Pr}\left(S_{t-1}=i \mid \Omega_{t-1}\right),
$$

gdzie prawdopodobieństwa przejścia $p_{i j}$ stanowią $M(M-1)$ parametrów do oszacowania.

Postać warunkowej funkcji gęstości zmiennej obserwowalnej:

$$
f\left(. \mid S_{t}=j, \Omega_{t-1}\right),
$$

wymaga przyjęcia założeń co do rodzaju rozkładu.

Oceny parametrów modelu mogą być uzyskane metodą największej wiarygodności. W tym celu wykorzystuje się funkcję wiarygodności postaci:

$$
L=\sum_{t=1}^{T} \log \operatorname{Pr} \sum_{i=1}^{M} f\left(y_{t} \mid S_{t}=j, \Omega_{t-1}\right) \operatorname{Pr}\left(S_{t}=j \mid \Omega_{t-1}\right) .
$$

Maksymalizacji funkcji (5) dokonuje się dobrze znaną metodą za pomocą algorymu EM (Expectation Maximization) ${ }^{10}$.

\footnotetext{
${ }^{10}$ Szczegóły, patrz: Krolzig (1998), str. 8.
} 


\section{WERYFIKACJA EMPIRYCZNA}

Zmowa producentów lysiny ${ }^{11}$ została im udowodniona w 1996 r. Próba obejmuje miesięczne przeciętne ceny lysiny na rynku USA w okresie 01/90 $-06 / 96^{12}$. W okresie tym, na podstawie zebranych dowodów (Connor, 2001) można wyróżnić następujące fazy (tabela 1).

Tabela 1. Statystyka cen lysiny (w centach za funt)

\begin{tabular}{|c|c|c|c|c|}
\hline Faza & $\begin{array}{c}\text { Liczba } \\
\text { miesięcy }\end{array}$ & Średnia & $\begin{array}{c}\text { Odchylenie } \\
\text { standardowe }\end{array}$ & $\begin{array}{c}\text { Współczynnik } \\
\text { zmienności }\end{array}$ \\
\hline 1. Konkurencja (01.90-07.92) & 31 & 102,90 & 16,22 & $15,8 \%$ \\
\hline 2. Zmowa (08.92-03.93) & 8 & 90,13 & 9,83 & $10,9 \%$ \\
\hline 3.Konkurencja (04.93-07.93) & 4 & 70,50 & 7,72 & $11 \%$ \\
\hline 4.Zmowa (08.93-06.95) & 23 & 110,30 & 8,55 & $7,8 \%$ \\
\hline 5.Konkurencja (07.95-06.96) & 12 & 102,50 & 9,51 & $9,3 \%$ \\
\hline
\end{tabular}

Źródło: obliczenia własne.

Celem badania empirycznego jest sprawdzenie, w jakim stopniu model o proponowanej specyfikacji może posłużyć do detekcji zmian typu reżimowego w wariancji procesu generującego dane, a tym samym detekcji faz zmowy. Weryfikacja taka jest możliwa dzięki znajomości historii zmowy, pod warunkiem, iż historia ta jest poprawnie określona (tzn. w trakcie procesu sądowego nie pominięto istotnych dowodów w sprawie).

Wstępnie sprawdzono dla dwu porównywalnych faz hipotezę o równości wariancji. Tabela 2 podsumowuje ten etap.

Tabela 2. Wartości statystyk dla testu równości wariancji w faz 1 i 4

\begin{tabular}{|c|c|c|}
\hline Bartlett & 7,6064 & $(0,005)$ \\
\hline Brown-Forsythe & 3,9206 & $(0,053)$ \\
\hline Test $F$ & 3,2106 & $(0,003)$ \\
\hline
\end{tabular}

W nawiasach () p- values.

Źródło: obliczenia własne.

$\mathrm{Na}$ podstawie testu można stwierdzić, iż wariancje w obu fazach są istotnie różne.

Następnie sprawdzono własności badanego szeregu pod kątem charakterystyki rozkładu oraz autokorelacji, stacjonarności i homoskedastyczności reszt. Wyniki tej części badania zawiera tabela 3 .

\footnotetext{
${ }^{11}$ Lysina to podstawowy aminokwas używany w przemysłowej hodowli drobiu, trzody i ryb.

${ }^{12}$ Dane pochodzą z: Connor (2000) załącznik A, tabela A2.
} 
Tabela 3. Charakterystyki szeregu

\begin{tabular}{|c|c|c|c|c|c|}
\hline Skośność & $-0,7652$ & $\begin{array}{c}\text { Test Jarque-Bera } \\
\text { na normalność } \\
\text { rozkładu }\end{array}$ & $\begin{array}{c}7,634792 \\
(0,021)\end{array}$ & Test ADF & $\begin{array}{r}-3,6277^{*} \\
(0,0073)\end{array}$ \\
\hline Kurtoza & 3,0818 & $\begin{array}{c}\text { Test Ljunga- } \\
\text {-Boxa dla po- } \\
\text { ziomów - Q(5) }\end{array}$ & $\begin{array}{c}145,26 \\
(0,000)\end{array}$ & Test KPSS & $0,16049^{* *}$ \\
\hline \multicolumn{3}{|c|}{ Test LM na heteroskedastyczność składnika losowego** } & $9,6859(0,002)$ \\
\hline
\end{tabular}

W nawiasach () p-values, * wartość statystyki $t$ (wartości krytyczne na poziomie $1 \% ; 5 \% ; 10 \%$ $(-3,519) ;(-2,900) ;(-2,587), * *$ wartość statystyki LM (asympt.wartości krytyczne na poziomie $1 \% ; 5 \% ; 10 \%-0,739 ; 0,463 ; 0,347)$, ***Test przeprowadzono dla oszacowanego modelu AR(2), który najlepiej opisuje średnią procesu (wyniki estymacji dostępne u autora).

Źródło: obliczenia własne.

Szereg jest skośny, odrzucona została hipoteza o rozkładzie normalnym oraz za pomocą testów o odmiennej konfiguracji hipotez potwierdzono stacjonarność szeregu. Po usunięciu autokorelacji występuje wyraźna heteroskedastyczność składnika losowego, co wskazuje na nieuwzględnione w modelu zależności w wariancji ${ }^{13}$.

W następnym etapie badania skonstruowano oraz oszacowano metodą największej wiarygodności szereg modeli typu MS(k)(AR(p))GARCH(p,q). Najlepsze rezultaty jeśli chodzi o własności modelu osiąnięto dla specyfikacji $\operatorname{MS}(2)(\operatorname{AR}(2)) \operatorname{GARCH}(1 ; 0)$ o postaci:

$$
y_{t}=\alpha_{0 S_{t}}+\sum_{m=1}^{2} \phi_{m} y_{t-m}+u_{t}
$$

gdzie:

$$
\begin{aligned}
& u_{t}=h_{t}^{1 / 2} e_{t} \text { oraz } e_{t} \sim \text { i.i.d. }(0,1), \\
& h_{t}=\beta_{0 S_{t}}+\beta_{1} u_{t-1}^{2}, \\
& S_{\mathrm{t}}=1,2 .
\end{aligned}
$$

Specyfikacja ta zakłada sterowanie obserwowalnym procesem ceny poprzez nieobserwowalny proces stochastycznym zmiennej stanu $s_{t}$, o którym zakłada się iż jest jednorodnym łańcuchem Markowa o 2 stanach i właściwej macierzy prawdopodobieństw przejścia pomiędzy stanami. Parametrami zależnymi od reżimu są stała oraz bezwarunkowa wariancja resztowa. Dodatkowo, niezależnie od reżimu średnią szeregu opisuje proces autoregresyjny rzędu 2 natomiast w wariancji obecny jest składnik GARCH( $1 ; 0)$. Wyniki estymacji modelu zawiera tabela 4.

\footnotetext{
${ }^{13} \mathrm{~W}$ pracy BCM zbadano ten sam szereg pod kątem efektu ARCH i stwierdzono występowanie tego efektu dla 15 opóźnień.
} 
Tabela 4. Wyniki estymacji MS(2)(AR(2))GARCH( $1 ; 0)$

\begin{tabular}{|c|c|c|c|c|}
\hline Parametr & Ocena & $p$-value & \multicolumn{2}{|c|}{ Dopasowanie i testy } \\
\hline$p_{11}$ & 0,94530 & ---- & L. wiarygodności & $-204,67$ \\
\hline$p_{22}$ & 0,86109 & --- & $R^{2}$ & 0,961 \\
\hline$\phi_{1}$ & 1,29048 & 0 & Skośność (reszty) & $-0,021$ \\
\hline$\phi_{2}$ & $-0,48502$ & 0 & Kurtoza (reszty) & 2,680 \\
\hline$\beta_{1}$ & 0,40597 & 0,094 & Jarque-Bera (reszty) & $0,326(0,849)^{*}$ \\
\hline$\alpha_{01}$ & 111,216 & 0 & Ljung-Box (reszty, Q(5)) & $3,206(0,668)$ \\
\hline$\alpha_{02}$ & 83,479 & 0 & Ljung-Box (reszty2, $\mathrm{Q}(5))$ & $4,699(0,454)$ \\
\hline$\beta_{01}$ & $\begin{array}{c}2,1049 \\
(4,4307)^{* *}\end{array}$ & ---- & $\begin{array}{c}\text { LM na } \\
\text { heteroskedastyczność } \\
\text { składnika losowego }\end{array}$ & $0,042(0,837)$ \\
\hline$\beta_{02}$ & $\begin{array}{c}3,4972 \\
(12,2304)^{* *}\end{array}$ & --- & $\begin{array}{c}\text { LM na pominięty efekt } \\
\text { ARCH }\end{array}$ & $4,0142(0,547)$ \\
\hline
\end{tabular}

*nawiasach () p- values, ** wariancja

Źródło: obliczenia własne w pakiecie TSM ver. 4.29.

Najistotniejsze jest pytanie, czy proponowany model może służyć założonemu celowi, a więc detekcji zmowy. Można to ocenić na podstawie precyzji detekcji reżimów. Na wykresie 1 przedstawiono odpowiednio wartości obserwowanej zmiennej i wykres prawdopodobieństw wygładzonych dla reżimu 1 (czyli prawdopodobieństw warunkowych przebywania procesu $\mathrm{W}$ stanie $s_{1}$ przy uwzględnieniu informacji z całej próby), wraz z zaznaczonym fazami zmowy.

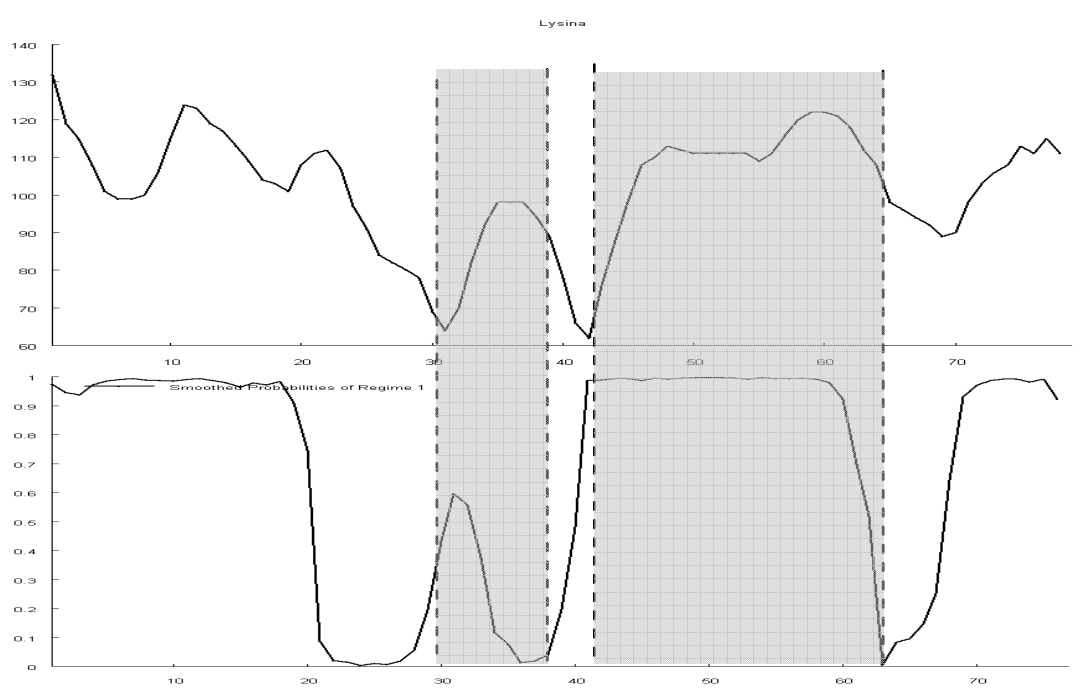

Wykres 1. Ceny lysiny oraz prawdopodobieństwa wygładzone

Źródło: opracowanie własne na podstawie tabeli 4.

Można zauważyć znaczną zgodność wykrytych przez model zmian reżimu wariancji i średniej z zaobserwowanymi fazami zmowy (szczególnie w przypadku fazy 2, która jest wykryta niemal idealnie). Wartość średniej wariancji 
składnika losowego w reżimie 1 jest ponad 2,5-krotnie większa niż w reżimie 2 co jest zgodne z założoną hipotezą teoretyczną. Prawdopodobieństwa $p_{i i}$ utrzymania się stanów „konkurencji” i „zmowy” są wysokie, co dobrze replikuje strukturę profilu strategii równowagi supergry. Niestety model ten wykrywa także zmiany reżimu dla innych okresów, co związane jest z tym, iż zmianom reżimowym podlega zarówno stała jak i wariancja. Wprawdzie ocena wartości stałej dla reżimu o niskiej wariancji (faza zmowy) jest znacząco wyższa niż dla reżimu konkurencji, co może potwierdzać tradycyjne rozumienie zmowy cenowej jednak na podstawie reżimów, ogólnie mówiąc, średniego poziomu ceny nie można jednoznacznie wnioskować o rodzaju równowagi, bez dodatkowych informacji statystycznych np. o poziomie popytu. Na wykresie 2 zaprezentowano zestawienie przebiegów zmian poziomu ceny oraz prawdopodobieństwa wygładzonego dla modelu gorzej dopasowanego (z przełączaniem wyłącznie w wariancji), lecz bardziej jednoznacznie wykrywającego poszczególne fazy ${ }^{14}$.

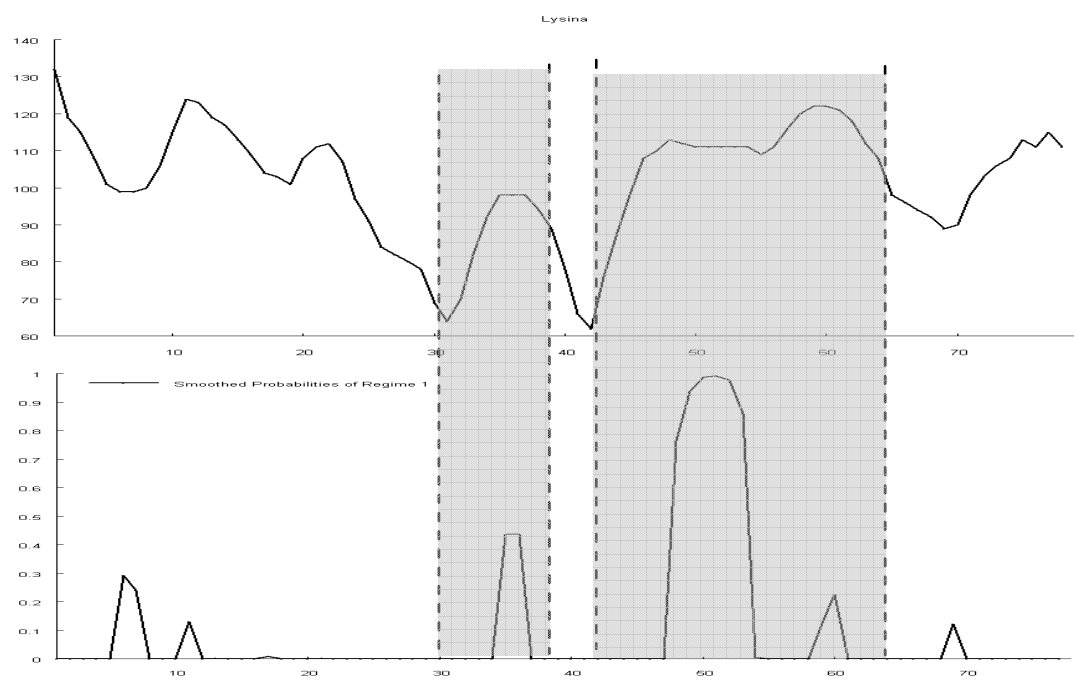

Wykres 2. Ceny lysiny oraz prawdopodobieństwa wygładzone

Źródło: opracowanie własne na podstawie tabeli 5.

Specyfikacja tego modelu to MS(2)-AR(1), oceny parametrów przedstawia tabela 5 .

\footnotetext{
${ }^{14}$ Komponent autoregresyjny w modelu przełącznikowym może pogorszyć jakość sygnału prawdopodobieństw filtrowanych, jeśli koryguje inne niż gaussowskie zakłócenia składnika losowego. Patrz np: Lahiri, Whang (1994).
} 
Tabela 5. Wyniki estymacji MS(2)-(AR(2))

\begin{tabular}{|c|c|c|c|c|}
\hline Parametr & Ocena & $\mathrm{p}$-value & \multicolumn{2}{|c|}{ Dopasowanie i testy } \\
\hline $\mathrm{p}_{11}$ & 0,68325 & --- & L. wiarygodności & $-236,45$ \\
\hline $\mathrm{p}_{22}$ & 0,96732 & --- & $\mathrm{R}^{2}$ & 0,851 \\
\hline$\phi_{1}$ & 0,94674 & 0 & Skośność (reszty) & $-0,115$ \\
\hline$\alpha_{0}$ & 104,641 & 0 & Kurtoza (reszty) & 2,452 \\
\hline$\beta_{01}$ & $\begin{array}{c}0,4331 \\
(0,1876)^{* *}\end{array}$ & & Jarque-Bera (reszty) & $1,134(0,567)$ \\
\hline$\beta_{02}$ & $\begin{array}{c}5,911 \\
(34,939)^{* *}\end{array}$ & & Ljung-Box (reszty, Q(5)) & $50,078 \quad(0)$ \\
\hline & & & $\begin{array}{c}\left.\text { Ljung-Box (reszty2 }{ }^{2}, \mathrm{Q}(5)\right) \\
\text { LM na } \\
\text { heteroskedastyczność } \\
\text { składnika losowego }\end{array}$ & $16,650(0,005)$ \\
\hline & & $\begin{array}{c}\text { LM na pominięty efekt } \\
\text { ARCH }\end{array}$ & $11,832(0,001)$ \\
\hline
\end{tabular}

*nawiasach () p- values, ** wariancja.

Źródło: obliczenia własne w pakiecie TSM ver. 4.29.

Model ten w zakresie detekcji rodzajów równowagi na podstawie wariancji jest bliższy faktycznie zaobserwowanej historii kartelu. Przede wszystkim średnia długość przebywania w każdym z reżimów $d_{s i}=\left(1-p_{i i}\right)^{-1}$ jest co do proporcji zgodna $\mathrm{z}$ historia, prawdopodobieństwo przejścia $\mathrm{z}$ fazy konkurencji do fazy zmowy jest wyższe oraz stabilność zmowy jest niższa. Porównując oba modele pod kątem wartości $p_{i i}$ bardziej zgodny z historią zmowy jest model 2 (średnia długość fazy zmowy 3,1 miesiąca podczas gdy dla modelu 1-16 miesięcy)

\section{PODSUMOWANIE}

Model przełącznikowy Markowa $\mathrm{z}$ komponentem przełączania w wariancji i/lub parametrami procesu GARCH ma wymienione na wstępie, niewątpliwe zalety teoretyczne, jeśli chodzi o detekcję zmowy na podstawie zmian wariancji ceny rynkowej. Na podstawie badania empirycznego można wstępnie stwierdzić poprawność detekcji przynajmniej w zakresie reżimów wariancji. Model w specyfikacji korzystniejszej po względem replikacji procesu jest lepiej dopasowany do danych niż modele użyte w pracy BCM (biorąc od uwagę wartość logarytmu funkcji wiarygodności). Należy jednak mieć na uwadze, iż weryfikacja empiryczna oparta została na jednym, unikatowym wprawdzie, lecz dość krótkim szeregu danych. Następnym etapem badań powinno być testowanie przyjętej metody na innych szeregach empirycznych (co jest trudne $\mathrm{z}$ uwagi na trudność pozyskania danych) lub też na szeregach generowanych dla różnych profili strategii zmowy. 


\section{LITERATURA}

Abrantes-Metz R., Froeb L., Geweke J., Taylor, C. (2006), A variance screen for collusion, „International Journal of Industrial Organization" 24, 467-486.

Athey S., Bagwell K., Sanchirico C. (2004), Collusion and price rigidity, „Review of Economic Studies" 71, 317-349.

Bejger S. (2004), Identyfikacja, pomiar i ocena siły rynkowej podmiotów gospodarczych oraz stopnia konkurencyjności branż z wykorzystaniem metodologii teorii gier, dysertacja doktorska.

Bolotova Y., Connor J.M., Miller D.J. (2008), The impact of collusion on price behavior: Empirical results from two recent cases, „International Journal of Industrial Organization” 26, $1290-1307$.

Connor J. (2000), Archer Daniels Midland: Price-fixer to the World, Staff paper No. 00-11, Department of Agricultural Economics, Purdue University, West Lafayette, IN.

Connor J. (2001), Our customers are our enemies: the lysine cartelof 1992-1995, „Review of Industrial Organization" $18,5-21$.

Davidson J. (2004), Forecasting Markov-switching dynamic, conditionally heteroscedastic processes, „Statistic and Probability Letters”, 68(2), 137-147.

Fong W.M. (1998), The Dynamics of DM/Pound exchange rate volatility: A SWARCH analysis, „International Journal of Finance and Economic"s 3, 59-71.

Fransens P., H., van Dijk D. (2000), Nonlinear time series models in empirical finance, Cambridge University Press.

Haltiwanger J., Harrington J.E. (1991), The Impact of Cyclical Demand Movements on Collusive Behavior, „RAND Journal of Economics”, 22 (1991), 89-106.

Hamilton J. D. (1989), A new approach to the economic analysis of nonstationary time series and the business cycle, „Econometrica” 57, 357-384.

Hamilton J. D., Susmel R. (1994), Autoregressive conditional heteroscedasticity and changes in regime, "Journal of Econometrics" 64, 307-333

Kośko M., Pietrzak M. (2007), Wykorzystanie przełacznikowych modeli typu Markowa w modelowaniu zmienności finansowych szeregów czasowych, [w:] Dynamiczne Modele Ekonometryczne, Z. Zieliński (red. naukowy) Wydawnictwo UMK, Toruń.

Krolzig H. M. (1998), Econometric Modelling of Markov-Switching Vector Autoregressions using MSVAR for Ox, Working paper.

Lahiri K., Whang J. G. (1994), Predicting Cyclical Turning Points with leading index in theMarkov Switching model., „Journal of Forecasting”, vol. 13, pp. 245-263.

Rotemberg J., Saloner G. (1986), A supergame theoretic model of business cycles and price wars during booms, „American Economic Review” 76, 390-407

Slade M. E. (1992), Vancouver's gasoline-price wars: An empirical exercise in uncovering supergame strategies, „Review of Economic Studies” 59, 257-276.

Stawicki J.(2004), Wykorzystanie lańcuchów Markowa w analizie rynku kapitałowego, Wydawnictwo UMK, Toruń.

Włodarczyk A., Zawada M. (2005), Przełqcznikowy model Markowa jako przykład niestacjonarnego modelu kursu walutowego, [w:] Dynamiczne Modele Ekonometryczne, Z. Zieliński (red. naukowy) Wydawnictwo UMK, Toruń,

\section{ECONOMETRIC TOOLS FOR COLLUSION DETECTION}

A b s t r a c t. Detection of overt or tacit collusion is a serious empirical problem. This paper outlines econometric methods of detection collusive equilibrium and focuses on the one which is consistent with equilibrium profile of proper dynamic model of collusion and relatively not data demanding, namely on marker of structural change in price volatility during collusive and competitive phase. As an proper econometric tool of discovery such an phenomenon Markov switch- 
ing model is proposed. This model with ARMA $(p, q)$ dynamics and switching variance and/or conditional heteroscedasticity in $\mathrm{ARCH}(\infty)$ form are ex-ante the most consistent with equilibrium profile structure and with players - observer information asymmetry. To verify proposed methodology an application to well known lysine conspiracy has been done.

$\mathrm{K}$ e y w o r d s: explicit and tacit collusion, collusive equilibrium, cartel detection, lysine, price variance, Markov switching model 